\title{
Visibility of Nutrition Research and Dissemination Challenges in French Speaking Sub-Saharan Africa: A Bibliometric Analysis
}

\author{
Ismael Ngnie-Teta ${ }^{1,2,{ }^{*}}$ and Dia Sanou ${ }^{2}$ \\ ${ }^{1}$ UNICEF Nutrition Division; ${ }^{2}$ Faculty of Health Sciences, University of Ottawa, Canada
}

\begin{abstract}
Although sub-Saharan Africa (SSA) is one of the regions in the world that is most affected by malnutrition and hunger, food science and nutrition related-publications by in-country-based authors from this region are rare. The objective of this paper is to analyze scientific production in French speaking SSA countries in the area of nutrition and food sciences (NFS). A bibliometric analysis was performed using the ISI Web of Knowledge database. We explored data for quantity and quality of publications between 1990 and 2009. Among the 21 sub-Saharan African countries with French as the official language, only 11 had more than 20 publications on NFS. This represents $4.7 \%$ of the total publications of these countries. The vast majority of the publications were in English $(76.7 \%)$ despite the official and primary academic language is French in all eleven countries. The average number of citations of articles in French was 0.9 per paper compared to 6.7 per paper published in English. France was the main collaborating country with Francebased researchers co-authoring $31.8 \%$ of the papers. Collaboration with other African countries was low and usually limited to neighbouring countries. In absolute numbers, Cameroon, Cote d'Ivoire and Benin were the most productive countries. When adjusted for population size, Mauritius, Gabon and Cameroon were the most productive countries per capita and when adjusted for average GDP, Cameroon, Burkina-Faso and Benin were the most productive. French speaking countries in Africa had a very low publication record in NFS and papers published in French were barely cited as compared to those published in English.
\end{abstract}

Keywords: Bibliometric, nutrition, food science, Africa, French.

\section{INTRODUCTION}

Sub-Saharan Africa (SSA) is one of the regions in the world that is most affected by malnutrition and hunger, with $21 \%$ of children under the age of five being underweight and $40 \%$ being stunted [1]. Recent estimates show that malnutrition contributes to about one third of child deaths [2]. Of the 40 countries with an under-five stunting prevalence of $40 \%$ or more, 23 are in Africa [2]. Further, a trend analysis by WHO suggested that by 2015, the prevalence of underweight will decrease in all regions of the world except in Africa, where an increase from $24 \%$ in 1990 to $27 \%$ in 2015 is anticipated [3].

Research substantially contributes to inform policy and identify relevant strategies to address health and nutrition issues. The improvement in child health in the past few years has been attributed to advances in health research [4]. Some authors pointed out important gaps and unequal distribution of knowledge production and use between poor and rich countries [5]. SSA is particularly underrepresented in health related scholarly literature [6-8]. Various bibliometric studies in the past years suggest that African scholarly publications accounted for only $1.4 \%$ of the world scientific literature [9]. Findings from health related disciplines including general medicine, cardiovascular

*Address corresponding to this author at the UNICEF, Route de l'Aéroport, BP

1146 N'Djamena, Chad, Canada; Tel: +235 22.52.89.89; Fax: +235 22.51.74.65; E-mail: ingnieteta@unicef.org disease, microbiology and bioinformatics highlight that the African contribution to global research production is persistently low representing as $1.2 \%[10,11]$.

Because of the huge burden of malnutrition, SSA has been a focus for public health nutrition research for decades and many papers have been published on the continent nutrition related issues [12]. Nevertheless few of those papers were from in-country-based authors from this region. A review of public health nutrition related articles completed by Aaron et al. (2010) showed that in 11 years (1998 to 2009), all 16 West African countries published only 412 articles (less than three articles per country per year) [13]. More interestingly, most articles (90\%) were published in English, and the total number of publications from the seven French speaking countries represents half of publications from Nigeria alone [13]. Dissemination challenges are more important for Francophone researchers since there is no single French peerreviewed journal with nutrition as a focus.

The purpose of this study is to examine scientific productivity using number of scholarly publications in French speaking SSA countries in nutrition and food science. The paper specifically aims at assessing the quantity (i.e. the number of articles published and trend in productivity) and the quality (i.e. the average citation index and $\mathrm{h}$-index) of published papers as well as the collaboration patterns over the past two decades. 


\section{METHODS}

This paper is an exploratory, descriptive investigation of publications from selected French speaking SSA countries in nutrition and food science. Data were obtained from the Thomson Reuters' Web of Knowledge, which is a search platform that provides access to the world's largest citation databases in sciences, social sciences, arts, and humanities. The Science Citation Index used to retrieve data for this work includes citations from 8,060 major journals across 173 disciplines.

A French speaking country was defined as a country with French as the official first language i.e. a country where French is the most used language in education and government administration. All publications listed in the two ISI fields ("Food Science and Technology" and "Nutrition and Dietetics") that had one of the selected countries in the address were considered. Bibliometric indicators (name of journal, names of authors, addresses, title of article, subject categories, year of publication, number of times cited, and language of publication) were downloaded into spreadsheets. In addition to the country address and the ISI fields above, the search was restricted to the time period between 1990 and 2009. Additionally, in the case of countries that had changed their names during this period (e.g Zaire to Democratic Republic of the Congo), both names were included in the search, and their data were combined. Furthermore, although one of the two Congo had more than 20 publications, Congo was later excluded from the analysis because it was not possible to differentiate between Democratic Republic of Congo (Capital Kinshasa) and the Republic of Congo (Capital Brazzaville). For some countries such as Cameroun, Cote d'Ivoire, Madagascar, and Mauritius, both French and English versions of their names were used to retrieve articles.

The bibliographic search was completed between May 2010 and July 2010 and included nutrition and food science related peer-reviewed articles published in each French speaking country. Analysis was later narrowed to countries with an average of at least one publication per year in nutrition and food science to allow for breakdown analysis by year and collaboration patterns. In alphabetic order, the countries included in this study are: Benin, Burkina-Faso, Cameroon, Cote d'Ivoire, Gabon, Madagascar, Mali, Mauritius, Niger and Senegal.

Key indicators used to assess the quantity and quality of scientific outputs in nutrition and food science

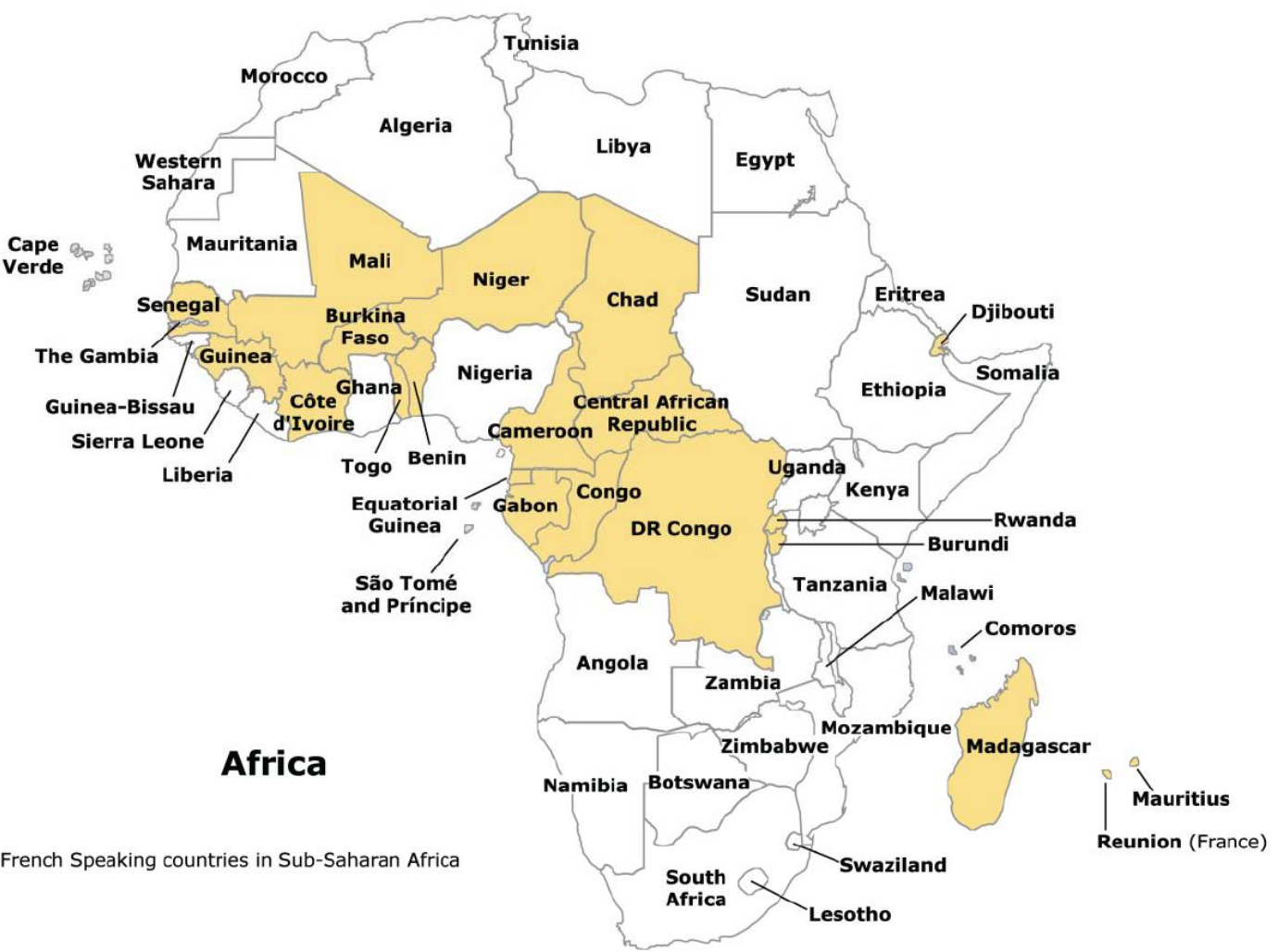

Figure 1: French speaking countries in sub-Saharan Africa. 
included the citation index, the h-index, and measures of international and domestic collaboration.

The citation index $(\mathrm{Cl})$ is a measure of the impact of a research or a scholar by tracking the number of times the designated author or a particular article is cited, assuming that influential scientists and important works are cited more often. The citation index is the basis of the calculation of journal impact factor. Because our interest was more in the dissemination rate and visibility of Francophone researchers' publications, the citation index was coupled with the h-index rather than the impact factor of the journal. The $h$-index is an indicator that measures the cumulative impact of a scholar's research output over time in a more nuanced fashion than straight citation counts. In other words, a researcher with an index $h$ has $h$ papers with at least $h$ citations [14]. In many cases, $h$ index is preferable to the impact factor because it combines an assessment of both quantity (number of papers) and quality (impact or citations) [15-17].

The collaboration pattern was assessed through the contact addresses of authors. International collaboration (IC) was defined as publication in which an African researcher or a researcher affiliated with an African institution has co-authored a paper with at least one international collaborator (outside Africa). Regional or within Africa collaboration (RC) was defined as coauthoring with at least one African collaborator (outside the target country) but with no international collaborator; and domestic collaboration (DC) as an in- country multi-author publication (only local researchers affiliated with different local institutions with no regional or international collaborator).

\section{RESULTS}

\section{Total Scholarly Production and Trends}

Twenty one sub-Saharan African countries with French as the official language were identified and considered (Figure 1). Only eleven were included in the analysis as one inclusion criterion was to have an average of at least one publication per year in nutrition or food sciences. In total, 18,418 articles were published by these 11 countries between 1990 and 2009. When all fields were combined Cameroon was relatively the most productive contributing a quarter of the publications while Mauritius contributed the least with only $3 \%$. Compared to the first decade (1990$1999)$, the scientific productivity in the second decade (2000-2009) is $116 \%$ higher, suggesting a substantial increase in recent years.

As shown in Figure 2, most countries' outputs increased steadily over time. This increase is particularly noteworthy in Benin (184\%), Burkina Faso (163\%), Madagascar (160 \%) and Mauritius (159\%), while Cote d'Ivoire (34\%) and Niger (7\%) showed the least increase. The snapshot on top-left in Figure 2 suggests that for these two countries with a smaller increase, the drop started in 1995 for Niger and 1998 for Cote d'Ivoire.

Table 1: Scientific Outputs in Selected French Speaking Sub-Saharan African Countries

\begin{tabular}{|c|c|c|c|c|c|c|c|}
\hline Country & $\begin{array}{c}\text { Total Scientific } \\
\text { Output (1990- } \\
2009)\end{array}$ & $\begin{array}{l}\text { Number of } \\
\text { articles per } \\
\text { million hbts* } \\
\text { per year }\end{array}$ & $\begin{array}{c}\text { Number of } \\
\text { articles } \\
1990-1999\end{array}$ & $\begin{array}{l}\text { Number of } \\
\text { articles } \\
2000-2009\end{array}$ & $\begin{array}{l}\text { Relative } \\
\text { increase }\end{array}$ & $\begin{array}{c}\text { Articles in } \\
\text { nutrition and } \\
\text { food sciences }\end{array}$ & $\begin{array}{c}\text { Articles in } \\
\text { nutrition and } \\
\text { dietetics only }\end{array}$ \\
\hline Benin & 1324 & 10.40 & 345 & 979 & $184 \%$ & 90 & 37 \\
\hline Burkina Faso & 1704 & 7.54 & 470 & 1234 & $163 \%$ & 60 & 35 \\
\hline Cameroon & 4493 & 14.59 & 1320 & 3173 & $140 \%$ & 264 & 66 \\
\hline Côte d'Ivoire & 2958 & 8.99 & 995 & 1331 & $34 \%$ & 142 & 35 \\
\hline Gabon & 1015 & 42.31 & 381 & 634 & $66 \%$ & 22 & 4 \\
\hline Madagascar & 1663 & 5.16 & 407 & 1058 & $160 \%$ & 38 & 12 \\
\hline Mali & 974 & 4.42 & 290 & 684 & $136 \%$ & 40 & 20 \\
\hline Mauritius & 590 & 25.07 & 165 & 428 & $159 \%$ & 40 & 14 \\
\hline Niger & 886 & 4.13 & 428 & 458 & $7 \%$ & 26 & 7 \\
\hline Senegal & 2811 & 13.67 & 901 & 1912 & $112 \%$ & 65 & 44 \\
\hline TOTAL & 18418 & 9.20 & 639 & 1120 & $116 \%$ & 787 & 274 \\
\hline
\end{tabular}

*hbts refers to inhabitants. 


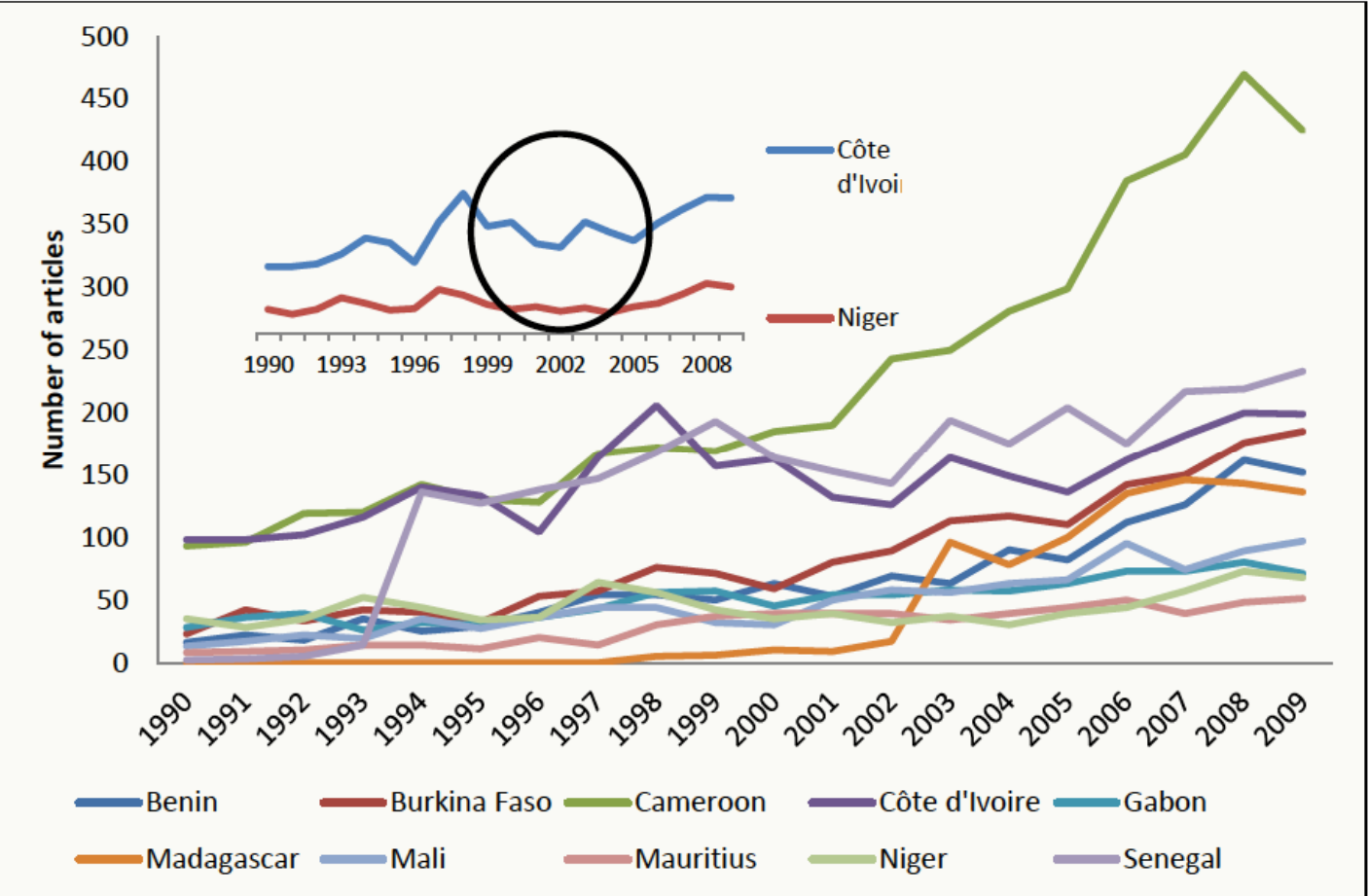

Figure 2: Trends in NFS publications in SSA between 1990 and 2009 and impact of social crisis in Cote d'Ivoire and Niger.

\section{Nutrition and Food Science-Related Publications}

Publications in nutrition and food science represented $4.7 \%$ of the total scholarly publications of these countries. Only a quarter $(24 \%)$ of these articles, representing about $1 \%$ of the total production, was published in nutrition and dietetics-related journals according to the Web of Science categories. Cameroon (a bilingual country), Cote d'Ivoire and Benin were the most productive countries in nutrition and food science
(Table 2). When adjusted for population size, Mauritius, Gabon and Cameroon were the most productive countries per capita and when adjusted for average GDP since 1990, Cameroon, Burkina-Faso and Benin were the most productive.

The vast majority $(76.7 \%)$ of the publications were in English although the primary academic language is French in all eleven countries. For the few that were published in French, the average number of citations

Table 2: Average Citation Index and h-Index of NFS Articles

\begin{tabular}{|c|c|c|c|c|c|c|c|c|c|}
\hline & \multicolumn{3}{|c|}{$\begin{array}{l}\text { Number of articles in nutrition/food } \\
\text { sciences }\end{array}$} & \multicolumn{3}{|c|}{ Average citation index } & \multicolumn{3}{|c|}{ Average $\mathrm{h}$-index } \\
\hline & Total & $\begin{array}{l}\text { Papers in } \\
\text { French }\end{array}$ & $\begin{array}{l}\text { Papers in } \\
\text { English }\end{array}$ & Total & $\begin{array}{l}\text { Papers in } \\
\text { French }\end{array}$ & $\begin{array}{l}\text { Papers in } \\
\text { English }\end{array}$ & Total & $\begin{array}{l}\text { Papers in } \\
\text { French }\end{array}$ & $\begin{array}{l}\text { Papers in } \\
\text { English }\end{array}$ \\
\hline Benin & 90 & 4 & 85 & 6.10 & 0.75 & 6.40 & 14 & 1 & 14 \\
\hline Burkina Faso & 60 & 4 & 61 & 6.86 & 0.50 & 7.28 & 12 & 1 & 12 \\
\hline Cameroon & 264 & 29 & 233 & 4.25 & 1.97 & 4.61 & 18 & 5 & 18 \\
\hline Côte d'lvoire & 142 & 64 & 74 & 5.54 & 1.14 & 9.55 & 14 & 3 & 14 \\
\hline Gabon & 22 & 1 & 22 & 3.77 & 1.00 & 3.90 & 5 & 1 & 5 \\
\hline Madagascar & 38 & 3 & 36 & 4.26 & 0.33 & 4.60 & 7 & 1 & 7 \\
\hline Mali & 40 & 0 & 40 & 6.43 & - & 6.43 & 10 & 0 & 10 \\
\hline Mauritius & 40 & 0 & 40 & 11.60 & - & 11.60 & 12 & 0 & 10 \\
\hline Niger & 26 & 0 & 26 & 9.92 & - & 9.92 & 6 & 0 & 6 \\
\hline Senegal & 65 & 9 & 56 & 5.51 & 0.49 & 6.32 & 11 & 1 & 11 \\
\hline Average & 79 & 11 & 67 & 6.42 & 0.88 & 7.06 & 11 & 1 & 11 \\
\hline
\end{tabular}


Table 3: Collaboration Patterns in NFS in Selected French Speaking SSA Countries

\begin{tabular}{|c|c|c|c|c|c|}
\hline Country & $\begin{array}{l}\text { Total number } \\
\text { of articles }\end{array}$ & $\begin{array}{l}\text { No of articles with no } \\
\text { external collaboration }\end{array}$ & $\begin{array}{l}\% \text { of articles with no } \\
\text { external collaboration }\end{array}$ & $\begin{array}{l}\text { Top two International } \\
\text { collaborators }\end{array}$ & $\begin{array}{l}\text { Top African } \\
\text { collaborator }\end{array}$ \\
\hline Benin & 90 & 9 & 10.0 & France - Netherlands & South Africa \\
\hline $\begin{array}{l}\text { Burkina- } \\
\text { Faso }\end{array}$ & 60 & 5 & 8.3 & France - Belgium & Senegal \\
\hline Cameroon & 264 & 87 & 33.0 & France - England & Nigeria \\
\hline Côte d'Ivoire & 111 & 57 & 51.4 & France - Switzerland & Morocco \\
\hline Gabon & 22 & 1 & 4.5 & France - Canada & Cameroon \\
\hline Madagascar & 26 & 5 & 19.2 & France - USA & French Polynesia \\
\hline Mali & 40 & 1 & 2.5 & France - Norway & Senegal \\
\hline Mauritius & 40 & 18 & 45.0 & England - Australia & Reunion \\
\hline Niger & 37 & 1 & 2.7 & USA - France & Nigeria \\
\hline Senegal & 65 & 7 & 10.8 & France - USA & Mali \\
\hline
\end{tabular}

was 0.9 per paper as compared to 7.1 per paper that was published in English. The $\mathrm{h}$-index of papers published in French was one as compared to 11 for their English counterparts.

\section{Collaboration Patterns and Impact of the Publications}

Of the 755 papers retrieved, most of them $74.7 \%$ (564) were co-authored by international or African collaborators and a quarter (191) was published without any out-of-country collaboration (data not shown). France was the main collaborating country, with France-based researchers co-authoring $31.8 \%$ of the papers. However, higher quality publications as measured by the Citation Index $(\mathrm{Cl})$ seemed to be from countries that mainly collaborated with authors from western English speaking countries particularly UK (Mauritius) and USA (Niger). Articles published in collaboration with non-African partners were more likely to be cited $(\mathrm{Cl}=7.3)$ as compared to those published without international collaboration $(\mathrm{Cl}=2.4)$.

\section{DISCUSSION}

In this exploratory study, we found that French speaking in-country-based scholars had a very low publication record in the area of nutrition and food science. Furthermore, papers published in French were barely cited as compared to those published in English.

Scientific productivity varied across countries and the top three performing countries were different when considering total productivity, population size adjustedproductivity and GDP adjusted-productivity. Only Cameroon with two official languages (French and English) was among the top three countries regardless of the adjustment. This observation confirms the already known overwhelming domination of the English language over French in the health literature [19].

The countries' total output increased steadily over time. The only exception to this steady increase was observed in Niger and Cote d'Ivoire between 1995 and 1998. This period coincided with socio-political instability and disturbance of peace experienced by those countries. The impact of political instability such as wars or other forms of civil strife on a country's economic growth, educational attainment and human capital was reported earlier by Deininger (2003) [18] Insecurity and uncertainty resulting from the instability could have affected international academic collaboration and encouraged brain drain of the most successful scholars.

Our results are in line with findings from previous research on bibliometric analysis that looked at French speaking publications in health journals. A study by Baethge et al. (2008) showed that among 5204 journals indexed in Medline in 2007, 88.6\% were in English, $1.9 \%$ in German, and $1.6 \%$ in French [20]. Today, it is estimated that more than $90 \%$ of new journals included in Medline are in English [21]. Certain et al. (2003) reported that only five African medical journals in French were indexed in Medline [19]. Recent data suggests that the ratio of French speaking 
articles have decreased over time, even in developed French speaking countries such as France and Switzerland because public health researchers are now increasingly publishing in English [22, 23]. The English language is especially important for scientific authors, as international communication in the medical field is mainly done in English [20, 24, 25]. With the introduction of the journal impact factor as a measure of a researcher's performance, many scholars who want their articles to reach a wider audience tend to publish in English. Because non-English journals are unlikely to be indexed in the prominent databases, they are less likely to be cited, contributing to their low citation index and h-index as observed in our study.

Similar findings were reported for Spanish and Germanic authors. Perez et al. (1997) reported that urological articles by Spanish authors were mainly published in English journals. In a bibliometric analysis of randomized control trials in healthcare, Galandi et al. (2006) concluded that German language general health care journals no longer played a role in the dissemination of trial results [24]. Additionally, Edouard (2009) reported that authors in countries where English language was the only or predominant language were reluctant to include non-English language references in the bibliographies of their publications [26]. This lowdissemination potential in peer-reviewed journals is thus reducing the visibility of nutrition research being done in French speaking countries.

Lack or paucity of scholarly publications may impede the international community's awareness of nutrition-related issues in these countries and may constitute a limiting factor to appropriate investment in nutrition since the international community is the major funder of nutrition interventions in sub-Saharan Africa. It may also hinder sufficient integration of culturally appropriate approaches in program design as well as the impact of researchers and their findings on policy changes.

The findings of this research call for specific innovative initiatives for and by French-speaking researchers. For example, during the pre-service training at the time of graduate studies, scientific English could be included in the curriculum.

Our findings seemed to suggest that North-South research networking and collaboration may be associated with likelihood of publication in high quality journals. This could be partly due to the fact that producing high quality data requires funding that is often provided by foreign collaborating partners. Therefore, such collaborations should be encouraged and supported by funding agencies. Capacity development initiatives such as grants or scientific writing and publication skills could also be included in the curriculum and the funding initiatives.

The editorial boards of influential peer-reviewed journals should be encouraged to accommodate French speaking submissions by translating abstracts of articles in French and devoting a quota to articles written in French. In the same vein, efforts should be made to introduce new high standard regional French journals in the field of nutrition and boost the quality and credibility of existing journals. Some revues and editors such have already taken steps towards publishing in more than one language. For example Global Health Promotion is publishing articles in English, French and Spanish. The Bulletin of the World Health Organization is providing abstract of all articles in 6 different languages. Cochrane is also trying to provide summary of reviews in languages other than English.

Findings from this bibliometric analysis should be interpreted in line with the study limitations. The first limitation is inherent in the source database used in this study. Web of Science has been criticized for not being comprehensive because not all the world's journals are indexed [27]. It is also believed that there is a coverage bias because ISI Web of Science indexes only journals written in English and mostly published in North America [27]. Using other databases might help mitigate the impact of this limitation. The second methodological issue is the restriction of journals of interest to two fields namely "Food Science and Technology" and "Nutrition and Dietetics". Many papers on nutrition get published in broader public health, biological or interdisciplinary journals. Further, publications in local journals, grey literature, and reports to government agencies and non-governmental and international organizations authored by Francophone researchers or institutions are often not indexed in databases.

Despite these limitations, the study clearly suggests that Francophone researchers are disadvantaged as the scientific community is dominated by the English language. French speaking countries, especially in sub-Saharan Africa, face a double challenge of a lack of competitive nutrition-oriented journals and a language barrier in addition to a very limited number of nutrition-focused research institutions. Moreover, it is 
likely that some, if not most, of the research outputs produced in these countries do not get published in science journals that are readily accessible to the international scientific community which creates the risk that valuable insights and results might be obscured [19].

\section{CONCLUSION}

French-speaking countries in Africa had a very low publication and citation record in the field of nutrition and food science. Papers published in French were barely cited as compared to the ones published in English and therefore the scientific information produced by francophone nutrition researchers in SSA has very limited visibility and reach only a local or regional audience.

These preliminary findings call for targeted capacity building initiatives for French-speaking SSA researchers that focus on grant and scientific writing and publication skills, more North-South research networking and collaboration, and commitment by the most influential international peer-reviewed journals to set aside quotas for francophone authors and provide research abstracts in French.

\section{ACKNOWLEDGEMENT}

We are grateful to Dr Mohamed Ayoya, Dr Kwado (Nana) Bosompra for their insights and Mses Suzanne Suh and Sabra Saleh for editing the preliminary version of the manuscript.

\section{REFERENCES}

[1] UNICEF. Tracking progress on child and maternal nutrition. A survival and development priority. United Nations Children's Fund (UNICEF) November 2009; p. 124.

[2] Black RE, Allen LH, Bhutta ZA, Caulfield LE, de Onis M, Ezzati M, et al. Maternal and Child Undernutrition: Global and regional exposures and health consequences. Lancet 2008; 371(9608): 243-60. http://dx.doi.org/10.1016/S0140-6736(07)61690-0

[3] de Onis M, Blossner M, Borghi E, Frongillo EA, Morris R. Estimates of global prevalence of childhood underweight in 1990 and 2015. JAMA 2004; 291(21): 2600-606. http://dx.doi.org/10.1001/jama.291.21.2600

[4] Dabis FJ, Orne-Gliemann F, Perez V, Leroy ML, Newell A, Coutsoudis $\mathrm{H}$, et al. Improving child health: the role of research. BMJ 2002; 324: 1444

http://dx.doi.org/10.1136/bmj.324.7351.1444

[5] Freeman $\mathrm{P}$, Robbins $\mathrm{A}$. The Publishing gap between rich and poor: the focus of AuthorAID. J Public Health Pol 2006; 27: 196-203.

http://dx.doi.org/10.1057/palgrave.jphp.3200071
[6] Arvanitis R, Waast R, Gaillard J. Science in Africa: a bibliometric panorama using PASCAL database, 1987-1997. Scientometrics 2000; 47: 457-73. http://dx.doi.org/10.1023/A:1005615816165

[7] Dahoun AM. Black Africa in the science citation index. Scientometrics 1999; 46: 11-18. http://dx.doi.org/10.1007/BF02766292

[8] Tijssen RJW. Africa's contribution to the worldwide research literature: New analytical perspectives, trends, and performance indicators. Scientometrics 2007; 71: 303-27. http://dx.doi.org/10.1007/s11192-007-1658-3

[9] UIS. What do bibliometric indicators tell us about world scientific output? Bulletin on Science and Technology Statistics, Issue no. 2, 2005; UNESCO Institute for Statistics, Montreal.

[10] Rahman M, Fukui T. Biomedical publication--global profile and trend. Public Health 2003; 117(4): 274-80. http://dx.doi.org/10.1016/S0033-3506(03)00068-4

[11] Uthman OA, Uthman MB. Geography of Africa biomedical publications: an analysis of 1996-2005. Int J Health Geogr 2007; 6:46. Online access August $12^{\text {th }} 2012$ at http://www.ncbi.nlm.nih.gov/pubmed/17927837.

[12] Chuang K-Y, Chuang Y-C, Ho M, Ho Y-S. Bibliometric analysis of public health research in Africa: The overall trend and regional comparisons. S Afr J Sci 2011; 107(5/6): Art. \#309,6 pages. doi:10.4102/sajs. v107i5/6.309

[13] Aaron GJ, Wilson SE, Brown KH. Bibliographic analysis of scientific research on selected topics in public health nutrition in West Africa: Review of articles published from 1998 to 2008. Global Public Health 2010; 5(6): S42-S57.

[14] Batista PD, Campiteli MG, Konouchi O, Martinez AS. Is it possible to compare researchers with different scientific interests? Scientometrics 2006; 68(1): 179-89. http://dx.doi.org/10.1007/s11192-006-0090-4

[15] Cronin B, Meho L. Using the h-index to rank influentia information scientists. J Am Assoc Inform Sci Techn 2006; (9): 1275-78.

[16] Glänzel W. On the opportunities and limitations of the $\mathrm{H}$ index. Sci Focus 2006; 1(1): 10-11.

[17] Hirsch JE. An index to quantify an individual's scientific research output. 16572 PNAS 2005; 102(46): 16569-72.

[18] Deininger K. Causes and consequences of civil strife: microlevel evidence from Uganda. Oxford Economics Papers. 2003; 55: 579-606 http://dx.doi.org/10.1093/oep/55.4.579

[19] Certain E. Medical research in French-speaking Africa: unrecognized research. Med Trop 2003; 63: 627-31.

[20] Baethge C. The languages of medicine. Deutsches Arzteblatt Int 2008; 105(3): 37-40.

[21] Castillo M. Is your journal indexed in Medline? AJNR 2011; 32: $1-2$ http://dx.doi.org/10.3174/ajnr.A2119

[22] Navarro FA. L'importance de l'anglais et du français sur la base des références bibliographiques de travaux originaux publiés dans La Presse Medicale. La Presse Medicale 1995 24: 1547-51.

[23] Olivier C, Casseyre $P$, Vayssairat $M$. French medical periodicals in the international scene? Bull Acad Natl Med 1999; 173(2): 141-144; discussion 144-7.

[24] Galandi D, Schwarzer G, Antes G. The demise of the randomized controlled trial: bibliometric study of the Germanlanguage health care literature, 1948-2004. BMC Med Res Method 2006; 6: 30. DOI 10.1186/1471-2288-6-30.

[25] Pérez Arbej JA, Cameo Rico MI, Arnáiz Esteban F, Martínez Pérez E, Nogueras Gimeno MA, Espuela Orgaz R, et al. Impact of Spanish-language urological publications in periodicals in the English language. Arch Esp Urol 1997; 50(5): 427-32. 
[26] Edouard B. Who cites non-English-language pharmaceutical articles? Ann Pharmacother 2009; 43(3): 549-50. http://dx.doi.org/10.1345/aph.1L490
[27] Morgan V, Janca A. Revisiting the journal impact factor. Austral Psych 2000; 8(3): 230-35.

http://dx.doi.org/10.1046/j.1440-1665.2000.00263.x

Received on 25-09-2012

Accepted on 08-12-2012

Published on 31-12-2012

http://dx.doi.org/10.6000/1929-4247.2012.01.02.7

(C) 2012 Ngnie-Teta and Sanou; Licensee Lifescience Global.

This is an open access article licensed under the terms of the Creative Commons Attribution Non-Commercial License (http://creativecommons.org/licenses/by-nc/3.0/) which permits unrestricted, non-commercial use, distribution and reproduction in any medium, provided the work is properly cited. 